\title{
A Titanium Cast Hollow Definitive Obturator Prosthesis for a Maxillectomy Patient
}

\author{
${ }^{1}$ Teny Fernandez, ${ }^{2}$ Sheela V Rodrigues, ${ }^{3} \mathrm{KR}$ Vijayanand
}

\begin{abstract}
Oral cancer necessitates the surgical removal of all or part of the maxilla. The extent of surgical resection is dependent on the size, location, and potential behavior of the tumor. The maxillectomy procedure leaves the patient with a defect that compromises of the integrity and function of the oral cavity, leading to hypernasal speech, fluid regurgitation into the nasal cavity, and impaired masticatory function. Rehabilitation of subtotal and total bilateral maxillectomy surgical defects is a complex challenge to the prosthodontist. Prosthetic rehabilitation of the surgical defect with the help of obturator is very important, because the resulting functional deficiencies have a detrimental effect on the quality of life and self-esteem of the patient.
\end{abstract}

Keywords: Definitive obturator, Maxillectomy, Obturator, Titanium prosthesis.

How to cite this article: Fernandez T, Rodrigues SV, Vijayanand KR. A Titanium Cast Hollow Definitive Obturator Prosthesis for a Maxillectomy Patient. Int J Prosthodont Restor Dent 2016;6(3):69-72.

\section{Source of support: Nil}

Conflict of interest: None

\section{INTRODUCTION}

Numerous epithelial subtypes of malignancies are found on the maxillary sinus: Adenocarcinoma, squamous cell carcinoma (SCC), adenoid cystic carcinoma, malignant melanoma, or salivary gland carcinoma. In SCC cases, concurrent chemoradiation along with debulking can be considered. ${ }^{1,2}$ The treatment is usually composed specifically of surgery alone or radiotherapy. The conventional surgical excision treatment of a maxillary oral SCC often leads to defects, which results in oroantral communication. ${ }^{3}$ The maxillectomy defects may be reconstructed by means of a prosthetic obturator or free flap transfer, but there is no consensus on the most appropriate technique.

A surgical treatment alone without reconstruction or obturation of the defect will result in air, food, and

\footnotetext{
${ }^{1}$ Senior Resident, ${ }^{2}$ Professor and Head, ${ }^{3}$ Lecturer

${ }^{1-3}$ Department of Prosthodontics, Government Dental College Alappuzha, Kerala, India

Corresponding Author: Teny Fernandez, Senior Resident Department of Prosthodontics, Government Dental College Alappuzha, Kerala, India, Phone: +919809804486, e-mail: tenyfernandez@gmail.com
}

liquid escaping into the sinus and nasal cavities, leading to severe dysfunction of speech and deglutition with significant reduction in quality of life of the patient. ${ }^{4}$ The obturator prosthesis plays an important role in functional recovery of postmaxillectomy patients. ${ }^{5}$ The patient is first treated with an interim obturator prosthesis, which is usually placed 7 to 10 days after surgery. ${ }^{6-11}$ A definitive obturator is fabricated approximately 3 to 4 months after surgery when the healing is complete. The definitive obturator impression should include the skingraft mucosal junction, lateral aspect of the orbital floor, and the velopharyngeal area depending on the extent of the defect. ${ }^{6,12}$ This case report describes the prosthetic rehabilitation of a maxillectomy patient with a titanium cast hollow obturator.

\section{CASE REPORT}

A 70-year-old female patient was referred from the Regional Cancer Centre, Thiruvananthapuram, to the Department of Prosthodontics, Government Dental College, Alappuzha, for prosthetic rehabilitation of a maxillectomy defect. The patient had undergone surgical maxillectomy 8 months back for the treatment of SCC. The chief complaints reported by the patient were nasal regurgitation of food and fluids while eating along with difficulty in speaking. An extraoral examination revealed facial asymmetry, with a lack of support for the lips and cheek on the right side (Fig. 1). Mouth opening of the patient was slightly restricted, with defective hypernasal

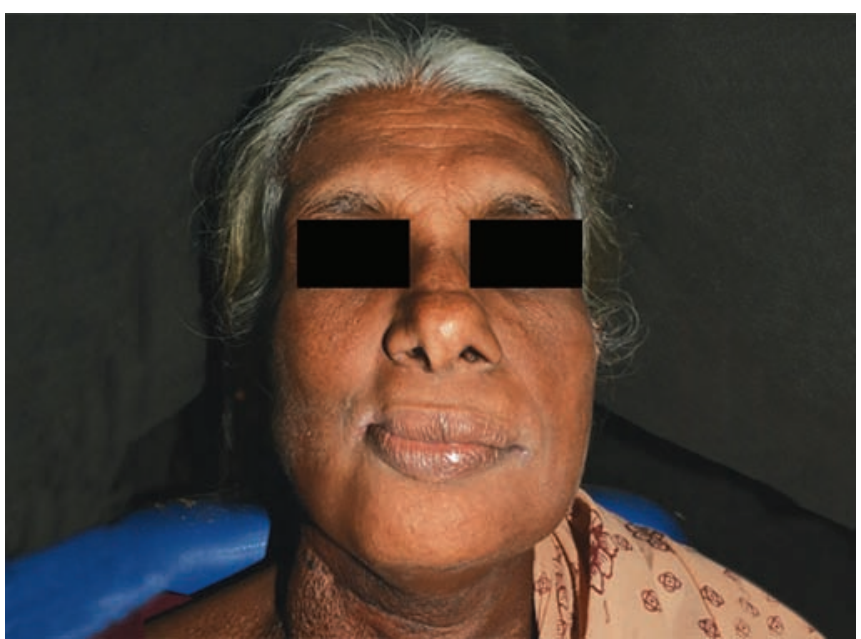

Fig. 1: Preoperative photograph 
speech. Intraoral examination revealed an Aramany type II palatal defect involving the right side of the arch (Fig. 2). After blocking out the undercuts of the defect with petrolatum-laden cotton, the primary diagnostic impressions were made using irreversible hydrocolloid impression material (Zelgan Alginate, Dentsply). The maxillectomy defect was outlined and the cast was surveyed for designing the titanium metal framework. A special tray with a uniform $2 \mathrm{~mm}$ wax spacer was fabricated for the final impression procedure. Rest seats were prepared on disto-occlusal of 26 and mesio-occlusal of 27 , to receive rests of embrasure clasp. Guide planes were prepared on distal of 23 and mesial of 25 . After completion of the mouth preparation, border molding of the defect side was done using polyvinyl siloxane putty in an incremental manner. The final impression was made using polyvinyl siloxane light body material (Aquasil, Dentsply) (Fig. 3). The design was transferred onto the master cast. A refractory cast was made by duplicating the blocked-out master cast using reversible hydrocolloid. An inlay wax pattern of the frame work was made on the

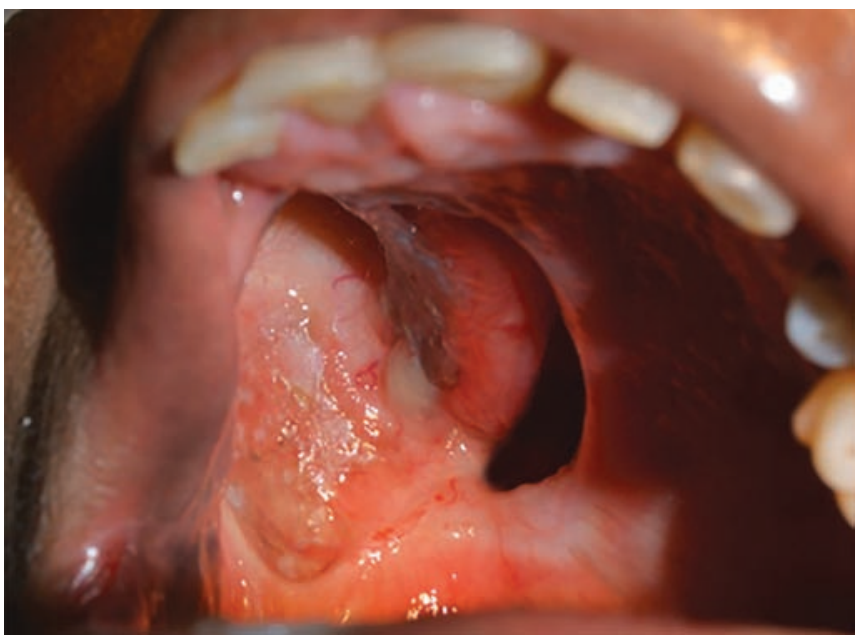

Fig. 2: Intraoral maxillectomy defect

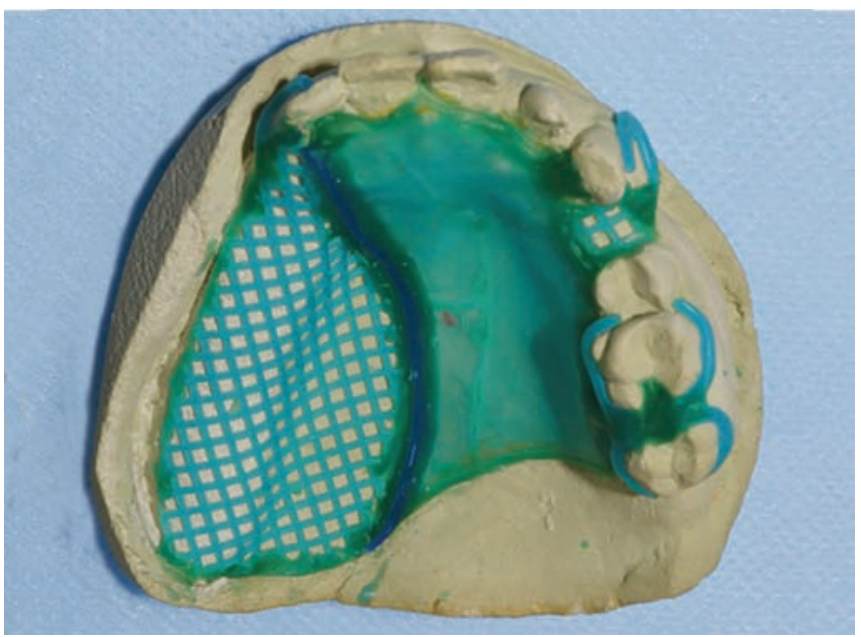

Fig. 4: Framework design for titanium casting refractory cast (Rolex Inlay wax) (Fig. 4). The wax pattern was cast in titanium (Fig. 5). The try-in of the metal framework was done in patient's mouth. The master cast was mounted on to a semiadjustable articulator using the jaw relation record. The try-in of the prosthesis was done after teeth setting. The try-in prosthesis was then acrilized (Brident, US) keeping the bulb hollow to reduce the weight of the obturator. A heat cure acrylic shim (Fig. 6) was fabricated using a duplicated cast and was attached to the metal framework (Figs 7 and 8). The hollowed prosthesis was tested for adequate seal and decrease in weight (Fig. 9). After standard finishing and polishing procedures, the prosthesis was inserted (Fig. 10). The patient showed considerable improvement in phonation, and the obturator was very effective in preventing nasal regurgitation of food and fluids. The patient was very much satisfied with the prosthesis (Fig. 11). Periodic recall appointments were scheduled for the evaluation of the prosthesis. The follow-up appointments showed satisfactory results with no deterioration of comfort and function with the prosthesis.

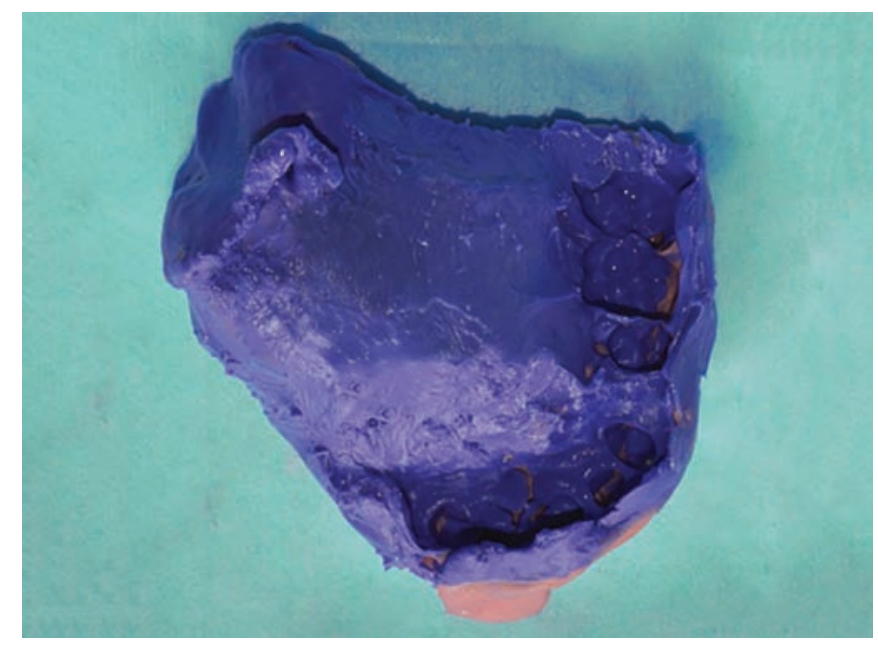

Fig. 3: Final impression of the defect

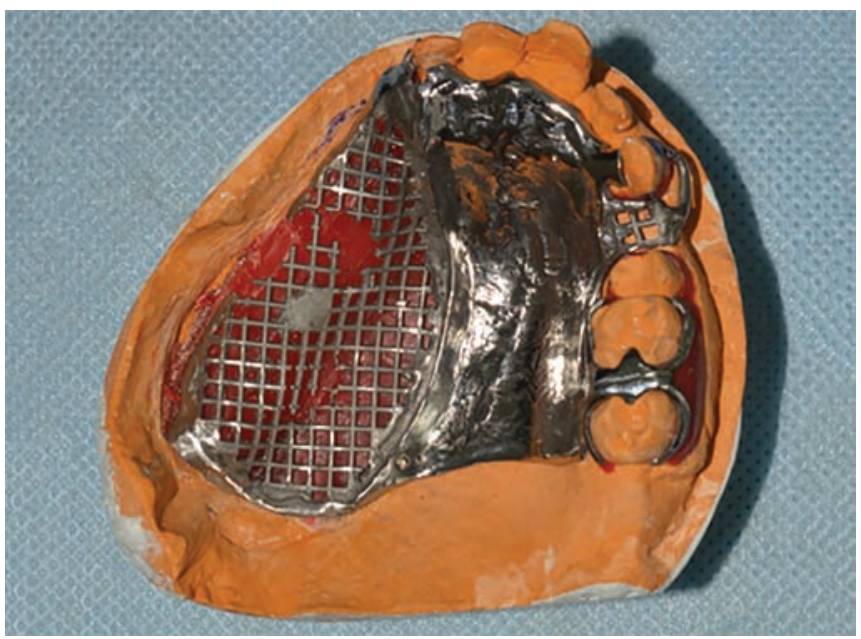

Fig. 5: Titanium framework after casting 


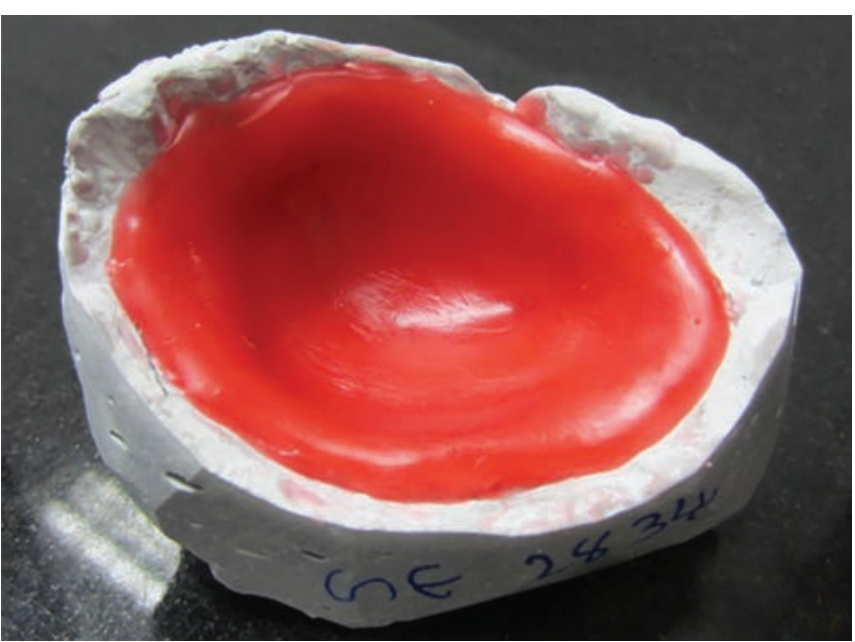

Fig. 6: Fabrication of acrylic shim

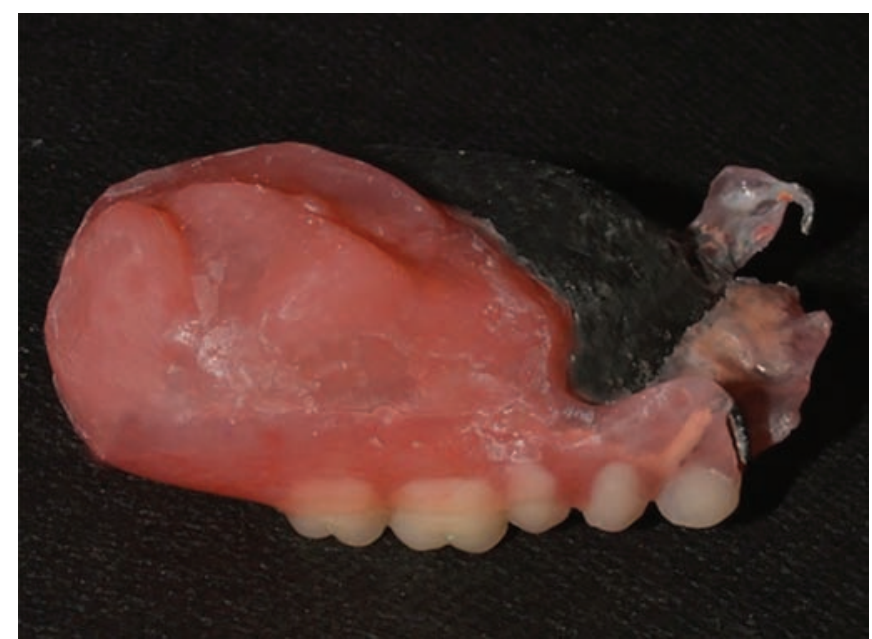

Fig. 8: The final prosthesis after joining

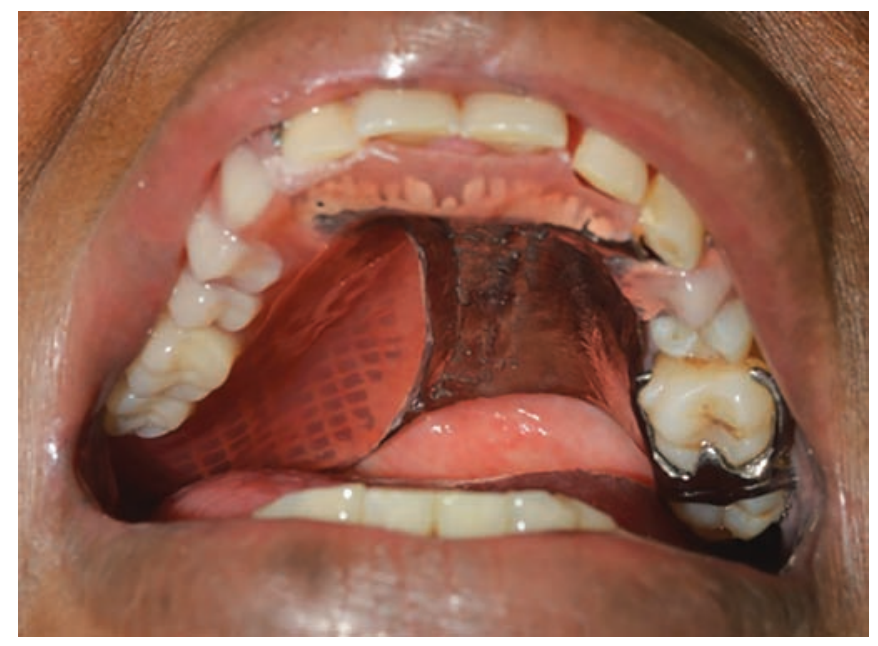

Fig. 10: The prosthesis inserted intraorally

\section{DISCUSSION}

Maxillectomy defects can be classified as partial, limited, medial, total, subtotal, radical, or extended. ${ }^{13}$ Although few researchers ${ }^{14}$ suggest that free surgical flaps offer the

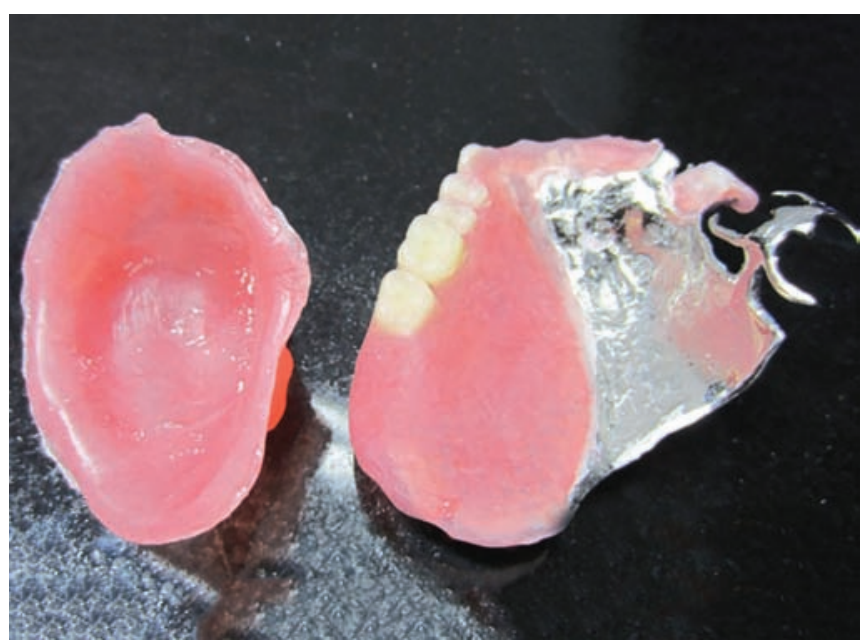

Fig. 7: Two parts of the prosthesis before joining

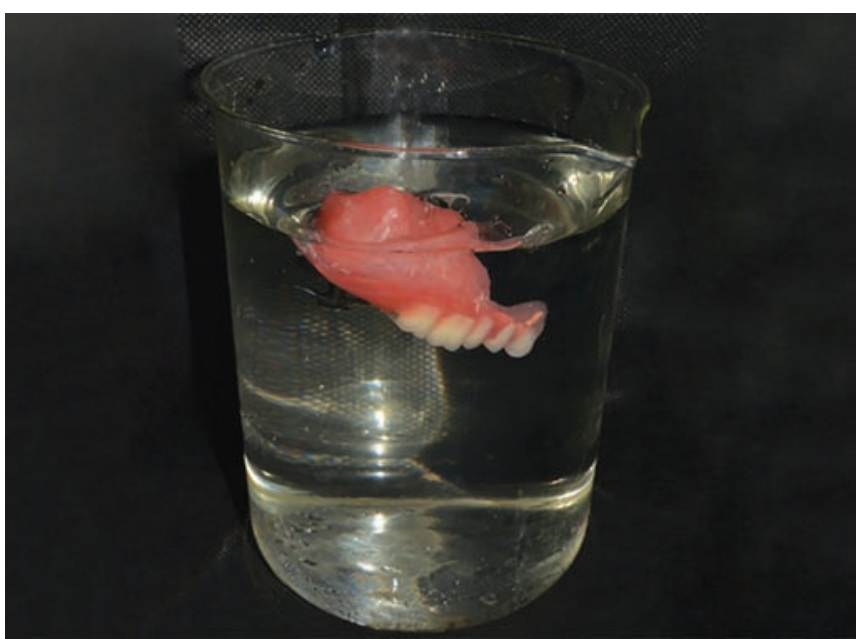

Fig. 9: Demonstration of hollowing

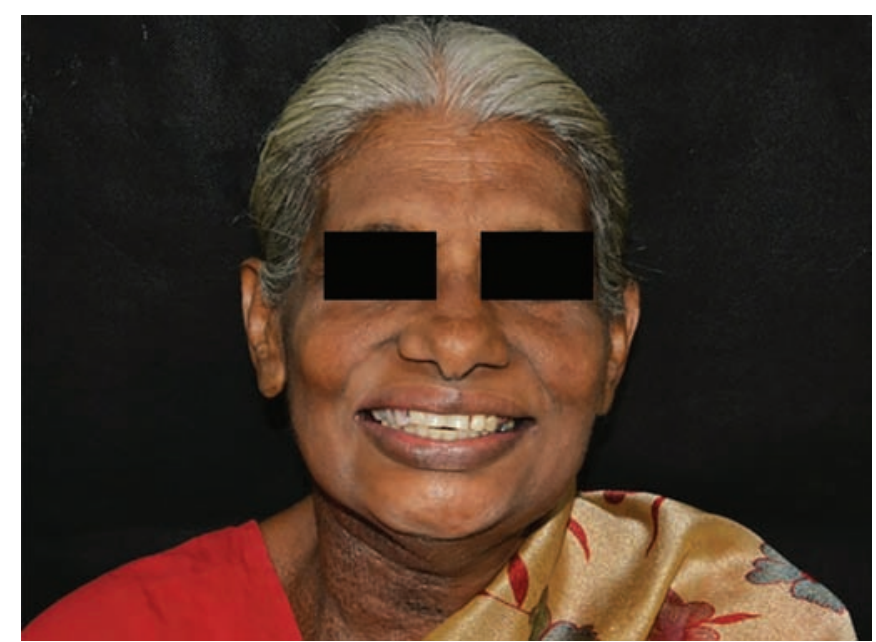

Fig. 11: Postoperative photograph

surgeon with an opportunity of dealing with the issues of prosthetic obturation like nasal leakage, cleansing, and regular prosthetic correction, it must be realized that surgical flap reconstruction remains associated with 
increased operation time, failure rates, and donor site morbidity. The fabrication of an obturator prosthesis shortens the operation time extensively and gives the opportunity of immediate rehabilitation. Prosthetic rehabilitation of maxillary defects can be categorized into three stages in which different type of obturator is fabricated in each stage. The obturator design may vary based on the classification system of the surgical defect. In this case, the support was gained from the remaining teeth and palate. Complete coverage of the remaining palate was planned to ensure maximum distribution of the load during function. Successful obturation of the maxillectomy defect is guided by the volume of the defect, and the positioning of postsurgical hard and soft tissues to be used for retention, stabilization, and support of the obturator. ${ }^{15}$ The weight of the prosthesis must be reduced to increase the retention of the obturator. ${ }^{12}$ The main advantages of titanium are its low density $\left(4500 \mathrm{~kg} / \mathrm{m}^{3}\right)$, good corrosion resistance, and high strength. The method of fabrication of the obturator in this case report involved a two-stage procedure in which the body of the obturator and its lid were processed separately and then joined together. The hollowing procedure further decreases the weight of the prosthesis. A closed hollow obturator is usually fabricated by attaching two parts using autopolymerizing acrylic resin ${ }^{16,17}$ or light-polymerized resin. ${ }^{18}$ The bulb and the lid must be sealed tightly after the procedure preventing the leakage of water into the hollow region promoting bacterial growth. The factors that ensure the daily routine use of the obturator by the patient are its comfortable prosthetic fit and functional success. Also, referral to a speech pathologist will contribute to its success by improving the ability of the patient to adequately speak and swallow. Patients who undergo maxillofacial prosthetic rehabilitation can resume their usual social habits in the normal way. ${ }^{19-22}$

\section{CONCLUSION}

Rehabilitation of the maxillectomy defect with an obturator prosthesis appears to be a functional and effective treatment modality. With proper diagnosis and treatment planning, the prognosis with the obturator will favor the patients to lead a life with self-confidence and respect. This case report discussed the prosthetic treatment of a maxillary defect with a titanium cast hollow definitive obturator.

\section{REFERENCES}

1. Itami J, Uno T, Aruga M, Ode S. Squamous cell carcinoma of the maxillary sinus treated with radiation therapy and conservative surgery. Cancer 1998 Jan 1;82(1):104-107.
2. Madison ML, Sorenson JM, Samant S, Robertson JH. The treatment of advanced sinonasal malignancies with pre-operative intra-arterial cisplatin and concurrent radiation. J Neurooncol 2005 Mar;72(1):67-75.

3. Cummings CW. Cummings otolaryngology: head and neck surgery. 4th ed. St. Louis (MO): Elsevier; 2004. p. 1604-1608.

4. Jacob FJ. Clinical management of the edentulous maxillectomy patient. In: Taylor TD, editor. Clinical maxillofacial prosthetics. Chicago (IL): Quintessence; 2000. p. 85-87.

5. Ono T, Kohda H, Hori K, Nokubi T. Masticatory performance in postmaxillectomy patients with edentulous maxillae fitted with obturator prostheses. Int J Prosthodont 2007 MarApr;20(2):145-150.

6. Curtis TA, Beumer J III. Restoration of acquired hard palate defects: etiology, disability, and rehabilitation. In: Beumer J, Curtis TA, Marunick MT, editors. Maxillofacial rehabilitation: prosthodontic and surgical considerations. St. Louis (MO): Ishiyaku EuroAmerica; 1996. p. 225-284.

7. Frame RT, King GE. A surgical interim prosthesis. J Prosthet Dent 1981 Jan;45(1):108-110.

8. Kouyoumdjian JH, Chalian VA. An interim obturator prosthesis with duplicated teeth and palate. J Prosthet Dent 1984 Oct;52(4):560-562.

9. Wolfaardt JF. Modifying a surgical obturator prosthesis into an interim obturator prosthesis: a clinical report. J Prosthet Dent 1989 Dec;62(6):619-621.

10. DaBreo EL, Chalian VA, Lingeman R, Reisbick MH. Prosthetic and surgical management of osteogenic sarcoma of the maxilla. J Prosthet Dent 1990 Mar;63(3):316-320.

11. Kaplan P. Stabilization of an interim obturator prosthesis using a denture duplicator. J Prosthet Dent 1992 Mar;67(3):377-379.

12. Keyf F. Obturator prostheses for hemimaxillectomy patients. J Oral Rehabil 2001 Sep;28(9):821-829.

13. Spiro RH, Strong EW, Shah JP. Maxillectomy and its classification. Head Neck 1997 Jul;19(4):309-314.

14. Genden EM, Wallace DI, Okay D, Urken ML. Reconstruction of the hard palate using the radial forearm free flap: indications and outcomes. Head Neck 2004 Sep;26(9):808-814.

15. Watson RM, Gray BJ. Assessing effective obturation. J Prosthet Dent 1985 Jul;54(1):88-93.

16. Habib BH, Driscoll CF. Fabrication of a closed hollow obturator. J Prosthet Dent 2004 Apr;91(4):383-385.

17. McAndrew KS, Rothenberger S, Minsley GE. An innovative investment method for the fabrication of a closed hollow obturator prosthesis. J Prosthet Dent 1998 Jul;80(1):129-132.

18. Kocacikli M, Yalug S, Yazicioglu H, Yilmaz C. Fabricating a hollow obturator with visible light-cured resin system. J Prosthodont 2008 Oct;17(7):596-598.

19. Elhag SA. Level of dry mouth and its effect on the quality of life in patients wearing maxillary obturator prostheses [Master's thesis]. Faculty of Dentistry, University of Khartoum; 2014. p. 1-70.

20. Elameen MM. Quality of life of patients wearing maxillary obturators [Master's thesis]. Faculty of Dentistry, University of Khartoum; 2014. p. 1-65.

21. Bailey LW, Edwards D. Psychological considerations in maxillofacial prosthetics. J Prosthet Dent 1975 Nov;34(5):533-538.

22. Gillis RE Jr, Swenson WM, Laney WR. Psychological factors involved in maxillofacial prosthetics. J Prosthet Dent 1979 Feb;41(2):183-188. 